\title{
Diet-induced obesity in ad libitum-fed mice: food texture overrides the effect of macronutrient composition
}

\author{
Charles Desmarchelier ${ }^{1 *}$, Tobias Ludwig ${ }^{2}$, Ronny Scheundel ${ }^{1}$, Nadine Rink ${ }^{3}$, Bernhard L. Bader ${ }^{2}$, \\ Martin Klingenspor ${ }^{3}$ and Hannelore Daniel ${ }^{1}$ \\ ${ }^{1}$ Molecular Nutrition Unit, ZIEL - Research Center for Nutrition and Food Sciences, Technische Universität München (TUM), \\ Gregor-Mendel-Strasse 2, 85350 Freising-Weibenstephan, Germany \\ ${ }^{2}$ Clinical Nutritional Medicine, ZIEL - Research Center for Nutrition and Food Sciences, Technische Universität München \\ (TUM), Gregor-Mendel-Strasse 2, 85350 Freising-Weihenstephan, Germany \\ ${ }^{3}$ Molecular Nutritional Medicine (Else Kröner-Fresenius Center), ZIEL - Research Center for Nutrition and Food Sciences, \\ Technische Universität München (TUM), Gregor-Mendel-Strasse 2, 85350 Freising-Weihenstephan, Germany
}

(Submitted 28 November 2011 - Final revision received 28 June 2012 - Accepted 2 July 2012 - First published online 6 August 2012)

\begin{abstract}
Diet-induced obesity in mice can be achieved through the use of diets with different macronutrient compositions and textures. We aimed at determining the contribution of macronutrient composition to obesity development and associated pathophysiological changes in mice. $\mathrm{C} 57 \mathrm{BL} / 6 \mathrm{~N}$ mice were offered a control, a high-fat or a Western-style diet, either as pellet (H for hard) or with identical composition in powder form (S for soft), resulting in C-S, C-H, HF-H, HF-S, W-H and W-S groups, respectively. Body fat distribution, expression levels of selected target genes in adipose tissues, clinical chemistry and hormone concentration in the blood, as well as liver TAG content were measured. The most striking finding was that all mice fed the different powder diets developed obesity with similar weight gain, whereas among the mice fed the pellet diets, only those given the HF and W diets became obese. This allowed us to separate diet-specific effects from obesity-mediated effects. Irrespective of the food texture, the W diet induced a more severe hepatosteatosis and higher activities of serum transaminases compared with the two other diets. Adipose tissue gene expression analysis revealed that leptin and adiponectin levels were not affected by the dietary composition per se, whereas uncoupling protein 1 and $11 \beta$-hydroxysteroid dehydrogenase type 1 levels were decreased by both dietary composition and changes in body weight. In conclusion, diets differing in macronutrient composition elicit specific pathophysiological changes, independently of changes in body weight. A diet high in both fat and sugars seems to be more deleterious for the liver than a HF diet.
\end{abstract}

Key words: Diet texture: Obesity: High-fat diets: Western diet: Intrahepatic TAG

Obesity has reached epidemic levels in Western countries. It reduces life expectancy and is considered as a key factor in the development of the metabolic syndrome ${ }^{(1)}$. Obesity results from a sustained imbalance between energy intake and energy expenditure by physical activity and is characterised by the storage of excessive TAG in adipose tissue and in additional ectopic depots, such as in the liver and muscle ${ }^{(2)}$. In understanding the genetic and environmental basis of obesity, animal models have proven to be useful by allowing manipulations technically or ethically not feasible in human subjects $^{(3)}$. Although monogenic ${ }^{(4)}$ and pharmacologically induced $^{(5)}$ models of obesity have provided insights into critical pathways, the polygenic nature of obesity calls for more realistic approaches to generate rodent-based obesity models.

In this context, high-fat diets have been applied to induce obesity in rodents since the early $1950 \mathrm{~s}^{(6)}$ and have been shown to cause pathophysiological changes similar to those found in human obesity ${ }^{(7)}$. These changes are straindependent: some strains, such as the AKR/J mouse, are obesity-prone while others, such as the SWR/J mouse strain, are obesity-resistant ${ }^{(8,9)}$. Dietary fat influences body adiposity quantitatively $^{(8,10)}$ but also qualitatively, depending on the fatty acid composition of the diet ${ }^{(10,11)}$. However, it is not yet clear whether fat per se has an obesogenic effect. Some studies have reported that animals fed an isoenergetic high-fat

Abbreviations: $11-\beta$ - $h s d-1,11 \beta$-hydroxysteroid dehydrogenase type 1 ; BAT, brown adipose tissue; C-H, control diet in pellet (H for hard) form; C-S, control diet in powder ( $\mathrm{S}$ for soft) form; EAT, epididymal adipose tissue; HF-H, high-fat diet in pellet form; HF-S, high-fat diet in powder form; IHTG, intrahepatic TAG; MAT, mesenteric adipose tissue; WAT, white adipose tissue; W-H, Western-style diet in pellet form; W-S, Western-style diet in powder form. 
diet had a greater body-weight gain than animals fed a control or low-fat diet $^{(12)}$, but others have failed to show any major differences $^{(13)}$. In human subjects, total energy intake, and not dietary fat content alone, has been shown to determine body fat accumulation ${ }^{(14,15)}$. Therefore, it seems sensible to induce obesity in rodent models not only by increasing the amount of dietary fat but also by means of hyperphagia. Cafeteria diets have been introduced for this purpose: animals are offered a choice of several palatable food items of variable composition, appearance and texture in addition to a (most often) non-purified diet. These diets have been shown to induce obesity based on hyperphagia in both rats and mice $^{(16,17)}$. Furthermore, diets used in feeding trials can substantially vary with respect to their hardness and diets presenting a hard texture have been shown to cause reduced body-weight gains in rodents ${ }^{(18-21)}$.

We decided to compare the effects of three different purified diets on body-weight development and physiological parameters in $\mathrm{C} 57 \mathrm{BL} / 6 \mathrm{~N}$ mice when identical diets were either provided in powder form or as pellets. Mice were given a control (C) diet ( $4.2 \%$ fat, w/w), a high-fat (HF) diet $(34 \%$ fat, $\mathrm{w} / \mathrm{w})$ or a Western-style (W) diet (17\% fat, w/w). The latter consisted of three differently flavoured diets, with exactly the same energy density and macronutrient composition, offered simultaneously to the mice. Based on the analysis of body fat compartments, gene expression in visceral and brown adipose tissue (BAT), plasma clinical chemistry and hormone/cytokine concentration, health status was assessed against an obese phenotype background.

\section{Materials and methods}

\section{Animals and experimental protocols}

Conventional 8-week-old male C57BL/6N mice were obtained from Charles River Laboratories and individually maintained in a controlled environment $\left(12 \mathrm{~h}\right.$ light-dark cycle, $22^{\circ} \mathrm{C}$ ), and had free access to water and food. A first cohort of mice was fed a non-purified diet (catalogue no. V1534; Ssniff $\mathrm{GmbH}$ ) for 2 weeks and thereafter divided into three groups ( $n$ 12) with a similar mean body weight. Mice were then fed for 12 weeks group-specific pellet diets ( $\mathrm{H}$ for hard) (catalogue no. E15000-04, E15741-34 and S0372-E0222, -E0242 and -E0262, respectively; Ssniff $\mathrm{GmbH}$ ). For the W group, mice had free access to three differently flavoured diets (peanut, banana and chocolate, respectively) given simultaneously and characterised by the same macronutrient composition and an increased content of both fat and sugars. The diet composition is provided in Table 1. Throughout the feeding trial, body weight, food and water consumption were recorded once per week. To correct food intake for loss of food, metal grids were placed below the food containers, allowing the collection of spillage. A second cohort of mice underwent the same dietary treatment but this time identical diets were given as powder ( $\mathrm{S}$ for soft) in small cups (non-purified diet: catalogue no. V1530; C: E15000-00; HF: E15741-30; W: S0372-E0220, -E0240 and -E0260). As all mice in this second cohort developed the same body weights, but lower than those observed in the first cohort, we decided to extend the length of the feeding trial to 18 weeks so that their mean body weight matched that of the mice from the first cohort fed the HF diet. Moreover, to determine whether the difference in age played a significant role in the effects observed, a third cohort of mice underwent the same dietary treatment but this time only the $\mathrm{C}$ and HF diets, in powder and pellet forms, were given to the mice for 12 weeks.

\section{Food intake test}

After 8 weeks of feeding, mice from the third cohort were subjected to a food intake test: the amount of food consumed 30 , 60 and $120 \mathrm{~min}$ after the diets were provided again following overnight deprivation was measured.

\section{Sample collections}

At the end of the feeding trial, mice in a non-fasting state were anaesthetised using isoflurane and blood was collected from the retro-orbital sinus. Mice were then killed by cervical dislocation. Liver, epididymal (EAT), retroperitoneal and perirenal, mesenteric (MAT), inguinal adipose tissue and interscapular BAT samples were collected, weighed with a precision balance and snap-frozen in liquid $\mathrm{N}_{2}$. In addition, at the end of the feeding trial, body size of mice from the third cohort was measured as the nasal-anus length. Their caecum was collected, weighed with a precision balance and snap-frozen in liquid $\mathrm{N}_{2}$. Moreover, during the last week of this feeding trial, faeces produced were collected, dried at $50^{\circ} \mathrm{C}$ to constant weight and ground. Faecal gross energy content was determined using an isoperibol bomb calorimeter (model number 6300; Parr Instrument $\mathrm{GmbH}$ ), with benzoic acid used as a standard. All procedures applied throughout the present study were conducted according to the German guidelines for animal care and approved by the state ethics committee under the reference number 209.1/211-2531-41/03.

\section{Chemical analysis}

Serum alanine and aspartate aminotransferase activities and glucose concentration were determined using Piccolo ${ }^{\circledR}$ Lipid Panel Plus Reagent Discs and a Piccolo Blood Chemistry Analyzer (Hitado Diagnostic Systems).

Serum insulin, leptin and resistin concentrations were determined using a MILLIPLEX MAP Mouse Serum Adipokine Panel (Millipore $\mathrm{GmbH}$ ) according to the manufacturer's instructions with an inter-assay $\mathrm{CV} \leq 12 \%$ and an intra-assay $\mathrm{CV} \leq 5 \%$.

To determine hepatic TAG content, liver samples were ground in liquid $\mathrm{N}_{2}$ and dissolved in $0.9 \% \mathrm{NaCl}$. TAG were extracted as follows: after centrifugation (Biofuge 15R; Heraeus Laboratory Centrifuges) for $10 \mathrm{~min}$ at $10000 \mathrm{~g}$, supernatants were incubated in alcoholic $\mathrm{KOH}\left(30 \mathrm{~min}, 70^{\circ} \mathrm{C}\right)$. Magnesium sulphate was added at a final concentration of $0 \cdot 15 \mathrm{~mol} / \mathrm{l}$ and, after centrifugation for $10 \mathrm{~min}$ at $10000 \mathrm{~g}$ TAG concentration was determined using a commercial enzymatic colorimetric kit following the manufacturer's instructions (Triglycerides liquicolor ${ }^{\text {mono; }}$ Human $\mathrm{GmbH}$ ). Values were 
Table 1. Composition of the different diets employed ${ }^{*}$

\begin{tabular}{|c|c|c|c|c|c|}
\hline & \multirow[b]{2}{*}{ Control } & \multicolumn{3}{|c|}{ Western style } & \multirow[b]{2}{*}{ High fat } \\
\hline & & Flavour 1 & Flavour 2 & Flavour 3 & \\
\hline GE (MJ/kg) & $18 \cdot 0$ & $21 \cdot 0$ & $21 \cdot 0$ & $21 \cdot 1$ & $25 \cdot 2$ \\
\hline ME (MJ/kg) & $15 \cdot 2$ & $17 \cdot 9$ & $18 \cdot 0$ & $18 \cdot 0$ & 21.4 \\
\hline$\%$ Protein & 23 & 17 & 17 & 17 & 19 \\
\hline$\%$ Fat & 11 & 36 & 36 & 36 & 60 \\
\hline$\%$ Carbohydrates & 66 & 47 & 47 & 47 & 21 \\
\hline Hardness (kP) & $2-5$ & & & & $26-34$ \\
\hline Casein & 240 & 190 & 206 & 200 & $276 \cdot 9$ \\
\hline Peanut meal, roasted, salted & - & 50 & - & - & - \\
\hline Maize starch, modified & 498 & 180 & 320 & 50 & - \\
\hline Maltodextrin & - & 181 & 50 & 64 & 158 \\
\hline Glucose & 100 & - & - & - & - \\
\hline Sucrose & - & 120 & 123 & 360 & 80 \\
\hline Cellulose & 50 & 46 & 50 & 40 & 60 \\
\hline Vitamin premix & 10 & 12 & 12 & 12 & 12 \\
\hline Mineral/trace elements & 60 & 60 & 60 & 60 & 61 \\
\hline L-Cystine & - & 2.5 & 2 & 2 & 3.5 \\
\hline L-Thr & - & 1.5 & 1.5 & 1.5 & - \\
\hline Choline chloride & 2 & 2 & 2 & 2 & 2.5 \\
\hline Salt $(\mathrm{NaCl})$ & - & 8.9 & $2 \cdot 4$ & $2 \cdot 4$ & 1 \\
\hline Butylhydroxytoluene & - & 0.1 & 0.1 & 0.1 & 0.1 \\
\hline Butter fat & - & 50 & 90 & - & - \\
\hline Beef tallow (premier jus) & - & 96 & - & 60 & 310 \\
\hline Soyabean oil & 40 & - & 2.5 & - & 30 \\
\hline Coconut fat & - & - & 77 & - & - \\
\hline Cocoa butter & - & - & - & 98.5 & - \\
\hline Cocoa powder & - & - & - & 46 & - \\
\hline Banana flavour & - & - & 1 & - & - \\
\hline Chocolate flavour & - & - & - & 1 & - \\
\hline Crude protein & 208 & 182 & 181 & 184 & 241 \\
\hline Crude fat & 42 & 171 & 170 & 170 & 340 \\
\hline Crude fibre & 50 & 52 & 50 & 54 & 60 \\
\hline Crude ash & 56 & 65 & 58 & 61 & 61 \\
\hline Starch & 488 & 189 & 319 & 62 & 11 \\
\hline Sugar & 108 & 124 & 128 & 362 & 82 \\
\hline Dextrins & - & 178 & 49 & 63 & 156 \\
\hline $\mathrm{Na}$ & 1.9 & $5 \cdot 6$ & 2.9 & 2.9 & 2 \\
\hline
\end{tabular}

GE, gross energy; ME, metabolisable energy calculated using Atwater factors.

${ }^{*}$ Nutrient composition is expressed as $\mathrm{g} / \mathrm{kg}$.

†For the Western-style group, mice had free access to the three differently flavoured diets given simultaneously.

normalised to the protein content of the samples, as determined by the Bradford assay ${ }^{(22)}$.

\section{RNA isolation}

Total RNA from the EAT, MAT and BAT was isolated using QIAzol $^{\circledR}$ lysis reagent (Qiagen $\mathrm{GmbH}$ ) according to the manufacturer's instructions and further purified using the QIAGEN RNeasy Mini Kit spin columns (Qiagen GmbH). RNA concentration was determined on a NanoDrop ND-1000 UV-Vis spectrophotometer (Peqlab Biotechnologie $\mathrm{GmbH}$ ) and its quality analysed with an Agilent Bioanalyzer (Agilent Technologies Deutschland GmbH) using Agilent RNA 6000 Nano Chips, according to the manufacturer's instructions.

\section{Real-time quantitative $P C R$}

For each sample, $10 \mathrm{ng}$ of isolated total RNA were used for quantitative PCR using the QuantiTect ${ }^{\circledR}$ quantitative, real-time one-step RT-PCR kit (Qiagen GmbH) following the supplier's protocol. Gene sequences for primers were retrieved from the database Mouse Genome Informatics (http://www. informatics.jax.org/). Primers were designed with VectorNTI Advance 10 (Invitrogen) and tested for specificity using BLAST (Basic local alignment search tool) analysis and conventional PCR. The primers used are listed in Table S1 (available online). Quantitative PCR was performed using SYBR Green I dye and a Mastercycler ep realplex apparatus (Eppendorf $A G)$. The following thermal cycling conditions were used: $30 \mathrm{~min}$ at $50^{\circ} \mathrm{C}$ (complementary DNA synthesis), $15 \mathrm{~min}$ at $95^{\circ} \mathrm{C}$ (RT enzyme inactivation) followed by forty cycles at $95^{\circ} \mathrm{C}$ for $15 \mathrm{~s}, 60^{\circ} \mathrm{C}$ for $30 \mathrm{~s}$ and $72^{\circ} \mathrm{C}$ for $30 \mathrm{~s}$. The PCR was concluded with a melting curve analysis of the PCR product $\left(1.75^{\circ} \mathrm{C} / \mathrm{min}\right)$. Quantification cycle $(\mathrm{Cq})$ values were retrieved from realplex 2.0 software (Eppendorf AG) and analysed following the efficiency-corrected method according to Pfaffl ${ }^{(23)}$, using $\beta$-actin as the invariant control to normalise the data. Primer efficiency was calculated with LinRegPCR ${ }^{(24)}$. 


\section{Statistical analysis}

For all groups, data are expressed as means with their standard errors. Except for correlation analysis, the first two cohorts of mice were always analysed separately. The third cohort of mice was analysed using two-way ANOVA. Statistical analyses were performed using Prism 4 software (GraphPad Software). Before ANOVA, data were tested for equality of variances and transformed if needed. Tukey's test was used for pairwise comparisons. Differences in liver weight were tested using ANCOVA in SAS (version 9.2; SAS Institute, Inc.) with body weight as a covariate. Differences in weight gain over the feeding period were tested using the MIXED procedure in SAS with time as a repeated factor ${ }^{(25)}$. The variables studied were subjected to seven covariance structures: unstructured covariance; compound symmetry; autoregressive order 1; autoregressive moving average order 1 ; heterogeneous compound symmetry; heterogeneous autoregressive order 1; Toeplitz. The goodness of fit of the models was compared using the Bayesian information criterion. Tukey's test was used as a post hoc test. For all tests, the bilateral $\alpha$ risk was $\alpha=0.05$.

\section{Results}

\section{Mice fed the two high-energy pellet diets developed} obesity

Feeding mice with the HF (HF-H) and the W (W-H) diets resulted in a significant increase in mean body weight $(P<0 \cdot 001)$, whereas mice fed the $\mathrm{C}$ diet $(\mathrm{C}-\mathrm{H})$ remained lean (Fig. 1(A)). Final body weight, cumulative food, energy and water intake, as well as the feed efficiency ratio and food spillage are shown in Table 2. Mice fed the different diets presented statistically different final body weights, with mice given the HF diet being the most obese (C-H: $29 \cdot 7$ (SEM 0.4) g; HF-H: 43.8 (SEM 1.1) g; W-H: 39.7 (SEM 1.3) g; $P<0.001)$. These results are in agreement with the measured energy intake since the higher the energy intake was, the heavier the mice were. Interestingly, the feed efficiency, defined as the amount of energy ingested for a weight gain of $1 \mathrm{~g}$, was approximately 4-fold higher in $\mathrm{C}-\mathrm{H}$ mice compared with $\mathrm{HF}-\mathrm{H}$ and $\mathrm{W}-\mathrm{H}$ mice.

\section{Mice fed the powder diets all developed obesity and ingested similar levels of energy}

Over the feeding trial, mice from all three groups showed a marked increase in body weight with no significant difference in weight gain over time $(P=0.889)$ as shown in Fig. 1(B). At the end of the feeding trial, mice did also not present statistically different final body weights (C-S: 45.1 (SEM 1.0) g; HF-S: 45.1 (SEM 1.3) g; W-S: 44.8 (SEM 1.3) g; $P=0.986$ ) and body weight was similar to that of mice fed the pellet HF (HF-H) diet. Mice fed the C-S diet had a higher food intake (3.8 (SEM 0.1) $\mathrm{g} / \mathrm{d})$ compared with mice fed the W-S (3.1 $(\operatorname{SEm} 0 \cdot 1) \mathrm{g} / \mathrm{d})$ and HF-S diets $(2.6(\operatorname{sem} 0 \cdot 0) \mathrm{g} / \mathrm{d})(P<0 \cdot 001$; Table 2). However, when energy intake rates were calculated by taking the different energy densities of the diets into
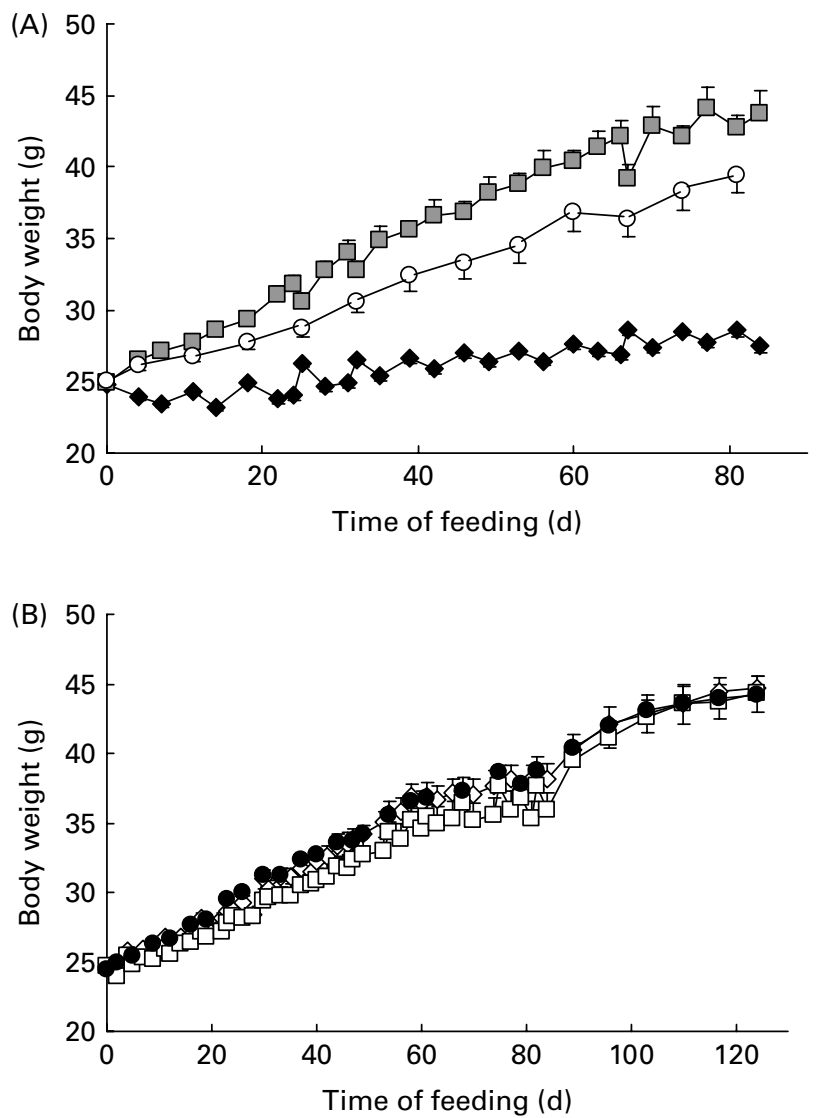

Fig. 1. Body-weight changes in mice receiving the different diets. (A) Bodyweight development in mice receiving the different diets provided as pellets (cohorts 1 and 3 ). Values are means, with their standard errors represented by vertical bars (C-H ( ) : $n$ 20; HF-H ( $\square)$ : $n$ 20; W-H (O): $n$ 12). (B) Body-weight development in mice receiving the different powder diets (cohorts 2 and 3 ). Values are means, with their standard errors represented by vertical bars (C-S $(\diamond): n 20$; HF-S $(\square): n 19$; W-S $(\bullet): n 12)$.

account (Table 1), mice in all three dietary groups presented very similar energy intake $(P=0 \cdot 111)$ and similar feed efficiencies $(P=0.944)$.

\section{Mice fed the pellet control diet displayed increased caecal weight}

Mice from the third cohort fed either the $\mathrm{C}$ or $\mathrm{HF}$ diet in powder and pellet form for 12 weeks showed the same features as described previously, with a lean phenotype when fed the C-H diet and an obese phenotype when fed the C-S, HF-S and HF-H diets (Fig. 1(A) and (B)). In this trial, we also determined whether any changes in overall body length could be observed; however, we did not detect any significant difference ( $P=0 \cdot 135$; two-way ANOVA), as shown in Table 2. Therefore, body-weight differences originated mainly from different body fat mass. A striking finding, however, was the large increase in caecal weight found only in mice fed the C-H diet. Relative to body weight, caecal weight in these animals was increased 1.8 -fold, accounting for $0.6 \%$ of body weight, compared with mice fed the C-S, HF-S and 
Table 2. Final body weight, cumulative food, energy, water and macronutrient intake in mice receiving the different diets either provided in pellet or powder form*

(Mean values with their standard errors)

\begin{tabular}{|c|c|c|c|c|c|c|c|c|c|c|c|c|c|c|}
\hline & \multicolumn{7}{|c|}{ Pellet } & \multicolumn{7}{|c|}{ Powder } \\
\hline & \multicolumn{2}{|c|}{ Control } & \multicolumn{2}{|c|}{ High fat } & \multicolumn{2}{|c|}{$\begin{array}{l}\text { Western } \\
\text { style }\end{array}$} & \multirow[b]{2}{*}{$P$} & \multicolumn{2}{|c|}{ Control } & \multicolumn{2}{|c|}{ High fat } & \multicolumn{2}{|c|}{$\begin{array}{l}\text { Western } \\
\text { style }\end{array}$} & \multirow[b]{2}{*}{$P$} \\
\hline & Mean & SEM & Mean & SEM & Mean & SEM & & Mean & SEM & Mean & SEM & Mean & SEM & \\
\hline Weight (g) & $29 \cdot 7^{\mathrm{a}}$ & 0.4 & $43 \cdot 8^{\mathrm{b}}$ & $1 \cdot 1$ & $39.7^{\mathrm{c}}$ & 1.3 & $<0.001$ & $45 \cdot 1$ & 1.0 & $45 \cdot 1$ & 1.3 & $44 \cdot 8$ & 1.3 & 0.986 \\
\hline Length $(\mathrm{cm})$ & $10 \cdot 0$ & 0.1 & $10 \cdot 3$ & $0 \cdot 1$ & & & & $10 \cdot 1$ & $0 \cdot 1$ & $10 \cdot 1$ & $0 \cdot 1$ & & & \\
\hline Food $(g / d)$ & $3 \cdot 8^{\mathrm{a}}$ & 0.0 & $3 \cdot 2^{b}$ & 0.0 & $3 \cdot 8^{\mathrm{a}}$ & 0.0 & $<0.001$ & $3 \cdot 8^{\mathrm{a}}$ & 0.1 & $2 \cdot 6^{b}$ & 0.0 & $3 \cdot 1^{\mathrm{c}}$ & 0.1 & $<0.001$ \\
\hline Food spillage $(\mathrm{g} / \mathrm{d})$ & $0.0^{\mathrm{a}}$ & 0.0 & $0.3^{b}$ & 0.0 & $0 \cdot 1^{\mathrm{c}}$ & 0.0 & $<0.001$ & ND & & ND & & ND & & \\
\hline Energy $(\mathrm{kJ} / \mathrm{d})$ & $68 \cdot 1^{a}$ & 0.5 & $81 \cdot 7^{\mathrm{b}}$ & 0.7 & $79 \cdot 2^{c}$ & 0.7 & $<0.001$ & $68 \cdot 4$ & 1.0 & $65 \cdot 3$ & 1.0 & $66 \cdot 0$ & $1 \cdot 1$ & 0.111 \\
\hline Feed efficiency $(\mathrm{kJ} / \mathrm{g})$ & $1693^{a}$ & 312 & $388^{b}$ & 21 & $490^{b}$ & 45 & $<0.001$ & 425 & 20 & 421 & 25 & 434 & 36 & 0.944 \\
\hline Faeces energy $(\mathrm{kJ} / \mathrm{d})$ & $5 \cdot 0^{\mathrm{a}}$ & 0.2 & $9 \cdot 6^{\mathrm{b}}$ & 0.4 & & & & $5 \cdot 5^{\mathrm{a}}$ & 0.1 & $6 \cdot 9^{c}$ & 0.4 & & & \\
\hline Water $(\mathrm{ml} / \mathrm{d})$ & $4 \cdot 1^{\mathrm{a}}$ & 0.1 & $2 \cdot 8^{\mathrm{b}}$ & 0.1 & $3 \cdot 3^{\mathrm{c}}$ & 0.1 & $<0.001$ & $3 \cdot 8^{\mathrm{a}}$ & 0.1 & $2 \cdot 7^{\mathrm{b}}$ & 0.1 & $3 \cdot 3^{\mathrm{c}}$ & 0.1 & $<0.001$ \\
\hline Protein $(\mathrm{g} / \mathrm{d})$ & $0 \cdot 7^{\mathrm{a}}$ & 0.0 & $0.5^{b}$ & 0.0 & $0.5^{c}$ & 0.0 & $<0.001$ & $0.7^{\mathrm{a}}$ & 0.0 & $0.4^{\mathrm{b}}$ & 0.0 & $0.5^{c}$ & 0.0 & $<0.001$ \\
\hline Fat $(\mathrm{g} / \mathrm{d})$ & $0.4^{\mathrm{a}}$ & 0.0 & $1.7^{b}$ & 0.0 & $1 \cdot 2^{c}$ & 0.0 & $<0.001$ & $0.4^{\mathrm{a}}$ & 0.0 & $1.3^{\mathrm{b}}$ & 0.0 & $1.0^{c}$ & 0.0 & $<0.001$ \\
\hline Carbohydrates (g/d) & $2 \cdot 1^{\mathrm{a}}$ & 0.0 & $0 \cdot 6^{b}$ & 0.0 & $1.5^{\mathrm{c}}$ & 0.0 & $<0.001$ & $2 \cdot 1^{\mathrm{a}}$ & $0 \cdot 1$ & $0.5^{\mathrm{b}}$ & 0.0 & $1 \cdot 3^{\mathrm{c}}$ & 0.0 & $<0.001$ \\
\hline
\end{tabular}

ND, not detectable.

${ }^{a, b, c}$ Mean values with unlike superscript letters were significantly different for a given variable $(P<0.05)$.

*Body weight, food and water consumption were recorded once per week.

HF-H diets with identical body weight $(P<0 \cdot 001$; two-way ANOVA; Table 3).

\section{Mice fed the control diet as powder or pellets displayed a similar food intake following food deprivation}

As shown in Table 4, when mice were presented their respective diet following overnight food deprivation, we did not observe any statistical difference in food intake after 30, 60 or $120 \mathrm{~min}$ between mice fed the $\mathrm{C}-\mathrm{H}$ and $\mathrm{C}-\mathrm{S}$ diets. Only mice given the HF-H diet presented an increased food intake after 60 and 120 min compared with mice fed the $\mathrm{C}$ diets.

\section{Blood chemistry and hormone/cytokine profiles}

Mice fed the pellet diets displayed marked differences in blood chemistry and hormone/cytokine profiles. Obese mice from the HF-H and W-H groups displayed significantly increased concentrations of glucose, insulin and resistin when compared with $\mathrm{C}-\mathrm{H}$ mice (Table 5). On the contrary, mice fed the different powder diets did not exhibit any significant differences in serum glucose, insulin and leptin concentrations; however, serum resistin concentration was significantly increased in mice fed the HF-S diet compared with C-S and W-S mice.

In mice fed the pellet diets, serum alanine aminotransferase activities were increased significantly in the $\mathrm{W}$ diet group, while in mice given the HF diet, the increase did not reach significance. For serum aspartate aminotransferase activities, we observed a trend towards an increase in mice fed the energy-rich diets $(P=0 \cdot 131)$. In mice fed the powder diets, serum alanine aminotransferase and aspartate aminotransferase activities were marginally increased $(P=0.051$ and 0.096 , respectively) in mice fed the $\mathrm{W}$ diet when compared with those receiving the $\mathrm{C}$ or $\mathrm{HF}$ diet.

\section{All diets - except the control pellet diet - caused increased fat depots, liver weight and intrahepatic TAG concentrations}

Organ weight, normalised to body weight, and intrahepatic TAG (IHTG) content are presented in Table 3. Mice fed the W diets presented significantly increased liver weight compared with mice fed the $\mathrm{C}$ or HF diet. IHTG content increased 3- to 4-fold in the HF and $\mathrm{W}$ groups given the pellet diets $(P<0.001)$. Feeding a $\mathrm{W}$ or $\mathrm{HF}$ diet in powder form also induced an increase in IHTG compared with the control mice $(P=0.029)$, although mice given the powder $C$ diet already displayed elevated concentrations. When liver weight was plotted against the final body weight in individual mice, in all cases - except for control mice fed the pellet $\mathrm{C}$ (C-H) diet that also showed no increase in body weight - a significant correlation was observed (Fig. 2). Moreover, the projected intercepts on the $x$-axis between 31 and $32 \mathrm{~g}$ body weight and the lack of an increase in liver weight in mice that stayed below $32 \mathrm{~g}$ body weight suggest that this body weight is the threshold from where on any weight gain, caused by any diet, proportionally increases liver weight.

For the weight of the four depots of white adipose tissue (WAT) collected from mice fed the powder diets, no significant difference was observed, with the exception of the EAT depot in the HF-S group $(P=0 \cdot 025)$. However, in mice given the HF and $\mathrm{W}$ diets provided as pellets, all fat depots increased significantly in relative weight when compared with the $\mathrm{C}$ group, which did not display a major weight gain. When compared with the powder diet groups, essentially similar fat depot sizes were observed, with the highest relative mass for the EAT depot, representing 5-6\% of total body mass (Table 3). The interscapular BAT was collected as well and similarly revealed a significant expansion with increased body mass. Whereas BAT mass accounted for $0.5-0.6 \%$ of final body mass in all mice that became obese, mice fed the powder $\mathrm{C}$ and $\mathrm{W}$ diets showed a further increase in 
interscapular BAT mass accounting for $0.75 \%$ of body mass $(P=0 \cdot 005)$, as shown in Table 3 .

\section{Gene expression analysis in adipose tissue}

We determined the mRNA expression levels of genes known to be associated with obesity in WAT and BAT (Table 6). In mice receiving the $\mathrm{HF}$ and $\mathrm{W}$ diets as pellets, an expected large increase in leptin mRNA expression levels was observed in the EAT and MAT samples, compared with mice receiving the pellet $\mathrm{C}$ diet and remaining lean. In mice fed the same diets as powder, the differences were not significant, which is in agreement with the observed similar fat depot masses and body weights in these three dietary groups. In all HF and $\mathrm{W}$ diet groups, regardless of whether given in pellet or powder form, a significant decline in $11 \beta$-hydroxysteroid dehydrogenase type 1 (11- $\beta$ - $h s d-1)$ mRNA expression levels was observed in both EAT and MAT depots. This suggests that any expansion of fat depots leads to a reduced mRNA expression level of this gene. In the MAT fat, the resistin mRNA expression level significantly increased in obese mice fed the pellet diets, whereas its expression level in EAT was significantly decreased in mice given the HF diet as pellets. In BAT, we observed a decreased mRNA expression level of the uncoupling protein $1(U c p-1)$ in all mice fed the HF and $\mathrm{W}$ diets, regardless of whether given in pellet or powder form. The uncoupling protein 3 (Ucp-3) mRNA level was reduced in obese mice fed the pellet diets when compared with those on the $\mathrm{C}$ diet $(\mathrm{C}-\mathrm{H})$ without significant weight gain. The mRNA expression level of the adipose TAG lipase (Atgl) was decreased in obese mice fed the pellet diets, whereas in mice given the powder diets, those receiving the W diet displayed an increase in Atgl mRNA expression level, despite almost identical body weight and relative BAT mass.

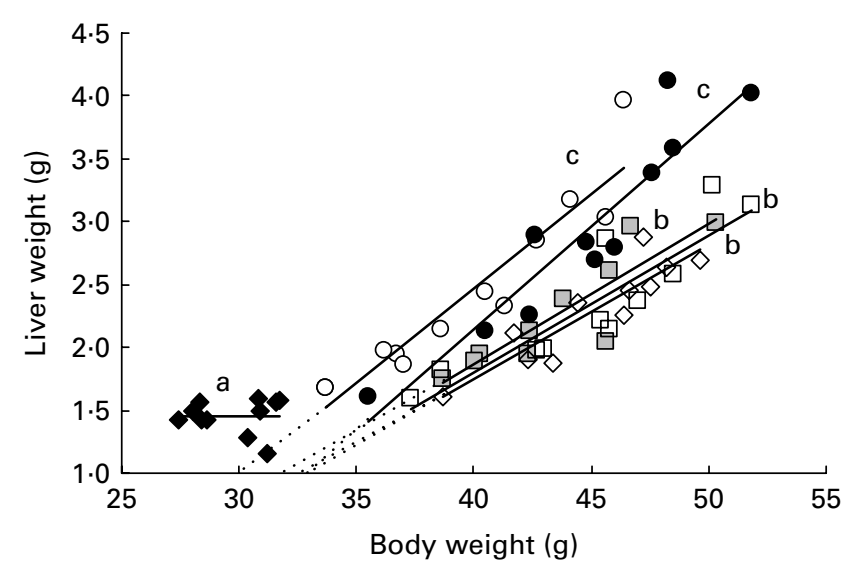

Fig. 2. Liver weight and intrahepatic $T A G$ in mice receiving the different diets. Across all mice and within lines, body weight was significantly correlated with liver weight: $r^{2} 0.67, n 66, P<0.001 ; \mathrm{C}-\mathrm{H}(>): r^{2} 0.00$, slope 0.00 , $n$ 11, $P=0.955$; HF-H (ם): $r^{2} 0.80$, slope $0.11, n 10, P<0.001 ; \mathrm{W}-\mathrm{H}(0): r^{2}$ 0.89 , slope $0.15, n 12, P<0.001$; C-S $(\diamond): r^{2} 0.81$, slope $0.11, n 11$, $P<0.001$; HF-S (口): $r^{2} 0.80$, slope 0.11, $n 11, P<0.001$; W-S $(\bullet): r^{2} 0.86$, slope $0.16, n 11, P<0.001$. ${ }^{a, b, c}$ For a given group, regression lines with unlike letters indicate a significantly different diet $\times$ texture interaction. There were significant body-weight $(P<0.001)$, diet $(P<0.001)$ and texture $(P<0.001)$ effects. 
Table 4. Food intake over short periods of time following overnight food deprivation* (Mean values with their standard errors)

\begin{tabular}{|c|c|c|c|c|c|c|c|c|c|}
\hline & \multicolumn{4}{|c|}{ Pellet } & \multicolumn{4}{|c|}{ Powder } & \multirow[b]{3}{*}{$P$} \\
\hline & \multicolumn{2}{|c|}{ Control } & \multicolumn{2}{|c|}{ High fat } & \multicolumn{2}{|c|}{ Control } & \multicolumn{2}{|c|}{ High fat } & \\
\hline & Mean & SEM & Mean & SEM & Mean & SEM & Mean & SEM & \\
\hline $30 \mathrm{~min}$ & 0.27 & 0.05 & 0.46 & 0.05 & 0.28 & 0.04 & 0.32 & 0.07 & 0.084 \\
\hline $60 \min$ & $0.40^{\mathrm{a}}$ & 0.03 & $0.64^{b}$ & 0.05 & $0.38^{a}$ & 0.03 & $0.46^{a, b}$ & 0.06 & 0.004 \\
\hline $120 \mathrm{~min}$ & $0.57^{a, b}$ & 0.04 & $0.70^{\mathrm{a}}$ & 0.05 & $0.47^{\mathrm{b}}$ & 0.04 & $0.58^{a, b}$ & 0.05 & 0.046 \\
\hline
\end{tabular}

\section{Discussion}

In the present study, we compared the effects of diets with different macronutrient compositions, provided either as pellets or powder to mice, on the development of obesity and some associated health status markers. In addition to a standard high-starch $\mathrm{C}$ diet and a HF diet, we used a W diet with three different flavours. In contrast to the original cafeteria diet introduced by Sclafani \& Springer ${ }^{(16)}$, comprising human food items added to a basal diet, we employed defined diets of identical macronutrient composition with $36 \%$ of energy coming from fat and $47 \%$ of energy from carbohydrates. This enabled us to precisely measure food and energy intake, which can be difficult with the original cafeteria diet due to its complexity ${ }^{(26)}$.

The most striking finding of the present study was that all mice, except those given the $\mathrm{C}$ pellet diet, gained weight with a similar slope and displayed final body weights of 40-45 g. Interestingly, mice fed the powder diets displayed almost identical daily energy intake rates. The estimated feed efficiency was consequently not different and amounted to approximately $430 \mathrm{~kJ} / \mathrm{g}$, independently of the diet. This was not the case for mice fed the pellet diets. Although, here, mice fed the HF diet had a significantly reduced food intake, energy intake in both HF and W diets was significantly higher than that in the $\mathrm{C}$ group and feed efficiency was markedly lower $(P<0.001)$, as shown in Table 2 . Thus, in powder-fed mice, the hyperphagia frequently associated with the consumption of energy-dense diets in rodents ${ }^{(27)}$ as well as in human subjects ${ }^{(28)}$ could not be observed here. All groups presented a similar energy intake and a similar weight gain. Although there is a controversy as to whether flavour variety in diets affects food intake ${ }^{(29,30)}$, we did not observe major effects except that food intake, when compared with mice fed the HF diet, was higher in mice fed the $\mathrm{W}$ diet in both pellet and powder forms.

The different results observed between the pellet and powder variants of the diets are of course striking and point at an effect of food texture on body-weight development. The impact of the hardness of the diet has already been addressed, and it has been shown that mice fed hard pellets had a lower body weight and improved blood glucose concentrations compared with mice fed soft or powder $\operatorname{diets}^{(18,19,21)}$. Rats have been shown to prefer soft pellets rather than the diet they are usually fed ${ }^{(31)}$. Long-term feeding of soft pellets induced a larger increase in body weight and body fat content and lower postprandial thermogenesis despite similar food intake rates when compared with pelletfed animals ${ }^{(20)}$. Rothwell et $a l^{(32)}$ observed that when rats were fed a low-fat or a HF diet given in powder form and greatly differing in energy density, all mice developed the same body weight with similar energy intake rates. In human subjects, diet hardness was found to be a significant determinant of waist circumference, independently of food intake, although no effect was observed on $\mathrm{BMI}^{(33)}$. Here, we show for the first time that a pellet-based highcarbohydrate/starch diet fails to trigger obesity, whereas the same diet given in powder form produces an obese

Table 5. Serum clinical chemistry and adipokine concentrations

(Mean values with their standard errors)

\begin{tabular}{|c|c|c|c|c|c|c|c|c|c|c|c|c|c|c|}
\hline & \multicolumn{7}{|c|}{ Pellet } & \multicolumn{7}{|c|}{ Powder } \\
\hline & \multicolumn{2}{|c|}{ Control } & \multicolumn{2}{|c|}{ High fat } & \multicolumn{2}{|c|}{ Western style } & \multirow[b]{2}{*}{$P$} & \multicolumn{2}{|c|}{ Control } & \multicolumn{2}{|c|}{ High fat } & \multicolumn{2}{|c|}{ Western style } & \multirow[b]{2}{*}{$P$} \\
\hline & Mean & SEM & Mean & SEM & Mean & SEM & & Mean & SEM & Mean & SEM & Mean & SEM & \\
\hline ALT (units/l) & $36^{\mathrm{a}}$ & 4 & $52^{\mathrm{a}, \mathrm{b}}$ & 5 & $73^{b}$ & 11 & 0.006 & 64 & 5 & 68 & 9 & 122 & 26 & 0.051 \\
\hline AST (units/l) & 76 & 8 & 94 & 9 & 103 & 11 & 0.131 & 103 & 7 & 93 & 13 & 138 & 19 & 0.096 \\
\hline Glucose $(\mathrm{mmol} / \mathrm{l})$ & $11 \cdot 8^{\mathrm{a}}$ & 0.5 & $14 \cdot 3^{b}$ & 0.5 & $15 \cdot 4^{\mathrm{b}}$ & 0.7 & $<0.001$ & $15 \cdot 2$ & 1.5 & $14 \cdot 8$ & $1 \cdot 2$ & $15 \cdot 0$ & 0.7 & 0.972 \\
\hline Insulin (pmol/l) & $19^{\mathrm{a}}$ & 3 & $118^{\mathrm{b}}$ & 21 & $120^{\mathrm{b}}$ & 35 & $<0.001$ & 337 & 92 & 410 & 81 & 367 & 118 & 0.865 \\
\hline Leptin (pmol/l) & $33^{a}$ & 7 & $505^{\mathrm{b}}$ & 69 & $272^{c}$ & 51 & $<0.001$ & 822 & 114 & 560 & 112 & 625 & 161 & 0.482 \\
\hline Resistin (pmol/l) & $47^{a}$ & 5 & $139^{b}$ & 16 & $122^{b}$ & 19 & $<0.001$ & $103^{\mathrm{a}}$ & 14 & $160^{\mathrm{b}}$ & 24 & $116^{\mathrm{a}}$ & 18 & 0.015 \\
\hline
\end{tabular}

ALT, alanine aminotransferase; AST, aspartate aminotransferase.

a,b,c Mean values with unlike superscript letters were significantly different for a given variable $(P<0.05)$. 


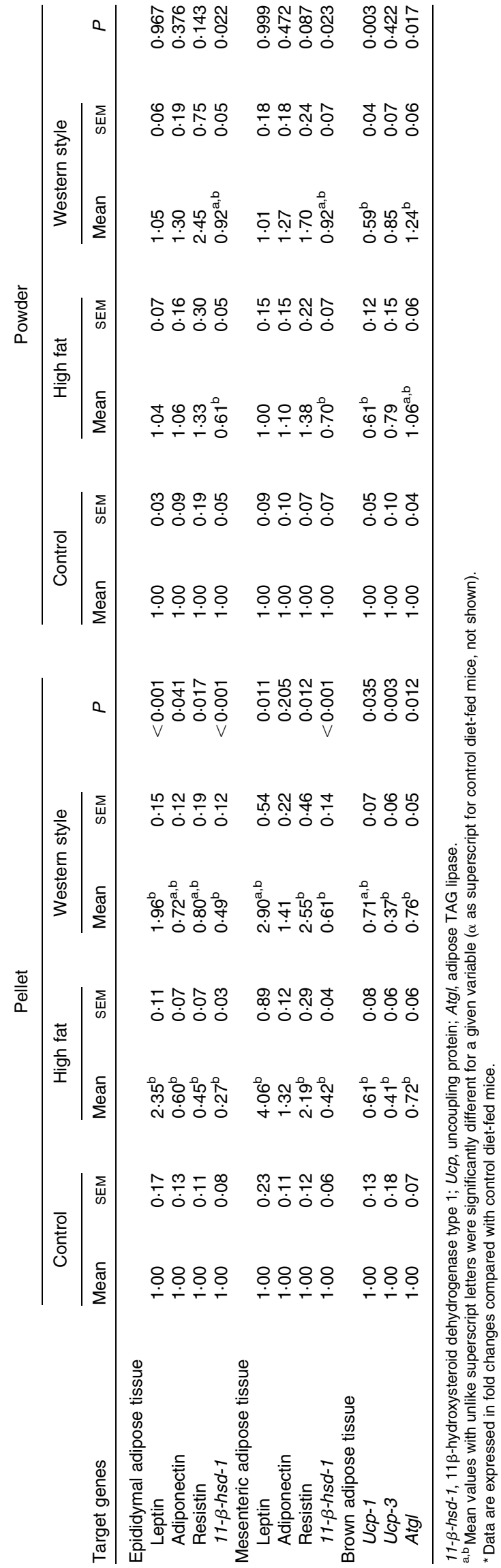

phenotype similar to a HF or W diet. While all mice receiving the high-carbohydrate $\mathrm{C}$ diets ingested very similar amounts of food and lost similar quantities of energy through faeces, they displayed quite different body-weight gains. The most striking difference, however, was that feed efficiency was 4-fold higher in the powder diet compared with the pellet variant.

The pellets, as provided here for both the HF and $\mathrm{W}$ diets, are softer in texture than those of the $\mathrm{C}$ diet with high starch content (Table 1). Thus, those very hard pellets might elicit a higher postprandial thermogenic response ${ }^{(34,35)}$, and mice consuming them may in addition need to utilise more energy for chewing (although we did not observe any difference in food intake over short periods of time following overnight food deprivation between the groups fed the powder or the pellet $\mathrm{C}$ diet, possibly due to adaptation of mice to their respective diet), for efficient handling (i.e. motility) in the stomach and intestine, and for digestion. That energy extraction in the small intestine may be limited from the high-starch pellet diet is suggested by a major increase in caecal mass found in these mice compared with all other animals. When non-digested starch reaches the caecum, microbiota mass increases and increased fermentation delivers SCFA that can be absorbed by the host. Yet, the energy delivered to the host is much less, accounting for about $7 \cdot 2 \mathrm{~kJ} / \mathrm{g}$ carbohydrate compared with $17 \cdot 2 \mathrm{~kJ} / \mathrm{g}$ when absorbed as glucose ${ }^{(36)}$

Since all mice given the powder diets had the same final body weight and obesity state, as judged by the expansion of fat depots, we could assess the specific effects of diet composition on selected metabolic parameters that characterise an obese state. The organ that was most affected by changes in dietary composition was the liver. Liver weight and IHTG concentrations (in $\mathrm{mg} / \mathrm{g}$ protein) increased proportionally to total body mass and independently of the diet after a 'threshold' body weight of about $32 \mathrm{~g}$ was reached. Increased concentrations of IHTG have been associated with hepatic and peripheral insulin resistance ${ }^{(37)}$ and are considered to represent a major determinant of the metabolic syndrome ${ }^{(38)}$. The W diet, regardless of whether presented as pellet or powder, increased liver weight more than the HF diet, suggesting that a higher dietary sucrose/dextrin intake may be more deleterious for the liver than a higher fat intake. Recently, Fabbrini et $a l .{ }^{(39)}$ demonstrated in human subjects that the IHTG content, but not visceral adipose tissue mass, was a marker of obesity-related metabolic dysfunctions. We observed in all obese mice - although not feed-deprived - markedly increased plasma glucose and insulin concentrations, suggesting also an impaired glucose tolerance. Plasma TAG did not differ among any group, whereas cholesterol and HDL concentrations were higher in obese mice.

Since adipose tissue plays a central role in energy homeostasis and the development of insulin resistance, notably through adipokines ${ }^{(40)}$, we measured the concentration of selected adipokines in serum and characterised changes in the mRNA expression levels of selected target genes involved in adipokine secretion or adipose tissue metabolism. Gene expression was studied in two visceral WAT depots and the interscapular BAT. Whereas MAT fat in particular is suspected to have a role in the aetiology of metabolic diseases ${ }^{(41)}$, the 
BAT has been shown to play a significant role in energy balance via non-shivering thermogenesis ${ }^{(42)}$.

Serum leptin concentration was significantly elevated in all obese mice, and there was no detectable effect of the diet. Since leptin concentration correlates with body fat mass and adipocyte size ${ }^{(43)}$, this was not surprising, based on the increase in body fat mass in all mice, except for the $\mathrm{C}-\mathrm{H}$ diet. Similarly, the mRNA expression level of leptin was higher in obese mice in EAT as well as MAT depots with no effect of the diet. Resistin showed significantly elevated mRNA expression levels in MAT depots when compared with mice given a $C$ pellet diet, and displayed a marginally significant increase when compared with mice given a $\mathrm{C}$ powder diet. Resistin, at least in rodents, has been shown to counteract insulin activity ${ }^{(44)}$, and therefore the finding that adipose tissue depots increase resistin expression may result from an adaptation to the elevated serum insulin, which could additionally enhance insulin resistance, in particular in mice fed pellets. Interestingly, in mice fed the powder diets, a HF diet induced a significant increase in circulating resistin concentration, although mice displayed similar insulin concentrations. The mRNA expression level of $11-\beta-h s d-1$ decreased significantly in all obese mice and more so in mice fed the HF and $\mathrm{W}$ powder diets. This suggests that any expansion of fat depots leads to a reduced mRNA expression level of this enzyme. $11-\beta-h s d-1$ is involved in glucocorticoid synthesis in adipose tissue and has been implicated in the pathology of the metabolic syndrome ${ }^{(45)}$. The present results are in accordance with those of Morton et al. ${ }^{(45)}$ who proposed that the decrease in $11-\beta-h s d-1$ expression might also represent a protective mechanism during chronic high fat feeding. Taken together, changes in gene expression observed in the different fat depots are mainly a measure of fat mass expansion and only subtle effects of diet composition are detectable.

In summary, we observed a very interesting phenomenon when inducing obesity in $\mathrm{C} 57 \mathrm{BL} / 6 \mathrm{~N}$ mice with two types of high-energy diets of identical macronutrient composition, provided either as pellet or in powder form. Regardless of the source of energy - whether based on a high-fat diet, or a W diet with lower fat but higher sucrose/dextrin content, or a starch-based $\mathrm{C}$ diet - all mice, when fed the powder diets, became obese with roughly the same weight gain. Although food intake rates were different, based on almost identical daily energy intake rates and identical feed efficiency values, the powder-fed mice displayed essentially the same proportional expansion of WAT depots and, as a consequence, possessed similar serum leptin concentrations. The only difference found between the diets was an increase in liver weight (absolute and relative to body mass) and IHTG concentrations in mice fed the $\mathrm{W}$ diet, which in this respect seems to be more deleterious to the liver than a pure HF diet providing $60 \%$ energy as fat. In mice fed the pellet diets, IHTG concentration was similarly elevated in the HF and W groups, although the latter displayed decreased body weight and WAT depot expansion compared with mice fed the HF diet. Most interestingly, both liver weight and IHTG concentrations increased proportionally to body mass in all mice after a threshold level of approximately $32 \mathrm{~g}$ body weight had been reached.
Finally, we would like to critically ask whether a pelletbased, high-carbohydrate/starch diet is a proper $\mathrm{C}$ diet when used for comparison with HF diets. Feeding diets with $>45 \%$ energy as fat is meanwhile accepted as a 'gold standard' to induce obesity in normal or transgenic mice models. The pellets of this $\mathrm{C}$ diet have an exceptionally hard texture and are therefore difficult to chew, to swallow and may need huge amounts of energy for handling in the gastrointestinal tract. They may also cause a loss of energy by the delivery of larger amounts of undigested starch to the microbiota and may after all produce an artificially 'lean phenotype'.

\section{Supplementary material}

To view supplementary material for this article, please visit http://dx.doi.org/10.1017/S0007114512003340

\section{Acknowledgements}

We thank Adelmar Stamfort for his help in statistical analysis, and Elmar Jocham and Johanna Welzhofer for their technical assistance. C. D. was funded by the European Union FP6 project Nutrient Sensing in Satiety Control and Obesity (NuSISCO, grant no. MEST-CT-2005-020494). The responsibilities of the authors are as follows: C. D., T. L., B. L. B. and H. D. designed the research; C. D., T. L., R. S. and N. R. conducted the research; C. D. and T. L. analysed the data; C. D., T. L. and H. D. wrote the paper; H. D., M. K. and B. L. B. had primary responsibility for the final content. All authors read and approved the final manuscript. The authors declare that they have no conflict of interest.

\section{References}

1. Haslam DW \& James WP (2005) Obesity. Lancet 366, 1197-1209.

2. Ravussin E \& Smith SR (2002) Increased fat intake, impaired fat oxidation, and failure of fat cell proliferation result in ectopic fat storage, insulin resistance, and type 2 diabetes mellitus. Ann N Y Acad Sci 967, 363-378.

3. Speakman J, Hambly C, Mitchell S, et al. (2008) The contribution of animal models to the study of obesity. Lab Anim 42, 413-432.

4. Zhang Y, Proenca R, Maffei M, et al. (1994) Positional cloning of the mouse obese gene and its human homologue. Nature 372, 425-432.

5. Brecher G \& Waxler SH (1949) Obesity in albino mice due to single injections of goldthioglucose. Proc Soc Exp Biol Med 70, 498-501.

6. Fenton PF \& Carr CJ (1951) The nutrition of the mouse: XI. Response of four strains to diets differing in fat content * two figures. J Nutr 45, 225-233.

7. Buettner R, Scholmerich J \& Bollheimer LC (2007) High-fat diets: modeling the metabolic disorders of human obesity in rodents. Obesity 15, 798-808.

8. West DB, Waguespack J \& McCollister S (1995) Dietary obesity in the mouse: interaction of strain with diet composition. Am J Physiol Regul Integr Comp Physiol 268, R658-R665.

9. Svenson KL, Von Smith R, Magnani PA, et al. (2007) Multiple trait measurements in 43 inbred mouse strains capture the 
phenotypic diversity characteristic of human populations. J Appl Physiol 102, 2369-2378.

10. Boozer CN, Schoenbach G \& Atkinson RL (1995) Dietary fat and adiposity: a dose-response relationship in adult male rats fed isocalorically. Am J Physiol Endocrinol Metab 268, E546-E550.

11. Buettner R, Parhofer KG, Woenckhaus M, et al. (2006) Defining high-fat-diet rat models: metabolic and molecular effects of different fat types. J Mol Endocrinol 36, 485-501.

12. Wade GN (1982) Obesity without overeating in golden hamsters. Physiol Behav 29, 701-707.

13. Woods SC, Seeley RJ, Rushing PA, et al. (2003) A controlled high-fat diet induces an obese syndrome in rats. J Nutr 133, 1081-1087.

14. Willett WC (1998) Is dietary fat a major determinant of body fat? Am J Clin Nutr 67, 556S-562S.

15. Willett WC \& Leibel RL (2002) Dietary fat is not a major determinant of body fat. Am J Med 113, Suppl. 9B, 47S-59S.

16. Sclafani A \& Springer D (1976) Dietary obesity in adult rats: similarities to hypothalamic and human obesity syndromes. Physiol Behav 17, 461-471.

17. Rothwell NJ \& Stock MJ (1988) The cafeteria diet as a tool for studies of thermogenesis. J Nutr 118, 925-928.

18. Ford DJ (1977) Influence of diet pellet hardness and particle size on food utilization by mice, rats and hamsters. Lab Anim 11, 241-246.

19. Koopman JP, Scholten PM, Roeleveld PC, et al. (1989) Hardness of diet pellets and its influence on growth of preweaned and weaned mice. $Z$ Versuchstierkd 32, 71-75.

20. Oka K, Sakuarae A, Fujise T, et al. (2003) Food texture differences affect energy metabolism in rats. J Dent Res $\mathbf{8 2}$, 491-494.

21. Nojima K, Ikegami H, Fujisawa T, et al. (2006) Food hardness as environmental factor in development of type 2 diabetes. Diabetes Res Clin Pract 74, 1-7.

22. Bradford MM (1976) A rapid and sensitive method for the quantitation of microgram quantities of protein utilizing the principle of protein-dye binding. Anal Biochem $\mathbf{7 2}$, $248-254$.

23. Pfaffl MW (2001) A new mathematical model for relative quantification in real-time RT-PCR. Nucleic Acids Res 29, e45.

24. Ruijter JM, Ramakers C, Hoogaars WM, et al. (2009) Amplification efficiency: linking baseline and bias in the analysis of quantitative PCR data. Nucleic Acids Res 37, e45.

25. Littell RC, Henry PR \& Ammerman CB (1998) Statistical analysis of repeated measures data using SAS procedures. J Anim Sci 76, 1216-1231.

26. Moore BJ (1987) The cafeteria diet - an inappropriate tool for studies of thermogenesis. J Nutr 117, 227-231.

27. Ramirez I \& Friedman MI (1990) Dietary hyperphagia in rats: role of fat, carbohydrate, and energy content. Physiol Behav 47, 1157-1163.

28. Rolls BJ (2000) The role of energy density in the over consumption of fat. J Nutr 130, 268S-271S.
29. Treit D, Spetch ML \& Deutsch JA (1983) Variety in the flavor of food enhances eating in the rat: a controlled demonstration. Physiol Behav 30, 207-211.

30. Naim M, Brand JG, Kare MR, et al. (1985) Energy intake, weight gain and fat deposition in rats fed flavored, nutritionally controlled diets in a multichoice ("cafeteria") design. J Nutr 115, 1447-1458.

31. Sako N, Okamoto K, Mori T, et al. (2002) The hardness of food plays an important role in food selection behavior in rats. Behav Brain Res 133, 377-382.

32. Rothwell NJ, Stock MJ \& Warwick BP (1985) Energy balance and brown fat activity in rats fed cafeteria diets or high-fat, semisynthetic diets at several levels of intake. Metabolism 34, 474-480.

33. Murakami K, Sasaki S, Takahashi Y, et al. (2007) Hardness (difficulty of chewing) of the habitual diet in relation to body mass index and waist circumference in free-living Japanese women aged 18-22 y. Am J Clin Nutr 86, 206-213.

34. LeBlanc J, Cabanac M \& Samson P (1984) Reduced postprandial heat production with gavage as compared with meal feeding in human subjects. Am J Physiol 246, E95-101.

35. Garrel DR \& de Jonge L (1994) Intragastric vs oral feeding: effect on the thermogenic response to feeding in lean and obese subjects. Am J Clin Nutr 59, 971-974.

36. Livesey G (1995) Metabolizable energy of macronutrients. Am J Clin Nutr 62, 1135S-1142S.

37. Korenblat KM, Fabbrini E, Mohammed BS, et al. (2008) Liver, muscle, and adipose tissue insulin action is directly related to intrahepatic triglyceride content in obese subjects. Gastroenterology 134, 1369-1375.

38. Marchesini G, Bugianesi E, Forlani G, et al. (2003) Nonalcoholic fatty liver, steatohepatitis, and the metabolic syndrome. Hepatology 37, 917-923.

39. Fabbrini E, Magkos F, Mohammed BS, et al. (2009) Intrahepatic fat, not visceral fat, is linked with metabolic complications of obesity. Proc Natl Acad Sci U S A 106, $15430-15435$.

40. Havel PJ (2004) Update on adipocyte hormones: regulation of energy balance and carbohydrate/lipid metabolism. Diabetes 53, Suppl. 1, S143-S151.

41. Yang YK, Chen M, Clements RH, et al. (2008) Human mesenteric adipose tissue plays unique role versus subcutaneous and omental fat in obesity related diabetes. Cell Physiol Biochem 22, 531-538.

42. Cannon B \& Nedergaard JAN (2004) Brown adipose tissue: function and physiological significance. Physiol Rev 84, 277-359.

43. Friedman JM \& Halaas JL (1998) Leptin and the regulation of body weight in mammals. Nature 395, 763-770.

44. Steppan CM, Bailey ST, Bhat S, et al. (2001) The hormone resistin links obesity to diabetes. Nature $\mathbf{4 0 9}, 307-312$.

45. Morton NM, Ramage L \& Seckl JR (2004) Down-regulation of adipose 11beta-hydroxysteroid dehydrogenase type 1 by high-fat feeding in mice: a potential adaptive mechanism counteracting metabolic disease. Endocrinology 145, 2707-2712. 